\title{
Dissolution of Bamboo Hemicellulose in 1-Butyl-3- Methylimidazolium Halide-based Ionic Liquids
}

\author{
Lin Yuan, ${ }^{\mathrm{a}, \mathrm{b}}$ Hong Peng, ${ }^{\mathrm{a}, \mathrm{c}, *}$ Lifang Hu, ${ }^{\mathrm{a}, \mathrm{c}}$ Ruobing Yu, ${ }^{\mathrm{d}}$ Wenyi Peng, ${ }^{\mathrm{b}}$ Roger Ruan, ${ }^{\mathrm{a}, \mathrm{c}}$ \\ Qi Xia, ${ }^{\text {a,c }}$ Yu Zhang, ${ }^{\text {a,c }}$ and Aihong Liu ${ }^{\text {e }}$
}

\begin{abstract}
Understanding the dissolution of hemicellulose in ionic liquids (ILs) is important in order to explore efficient utilization of ILs for fractionating lignocellulose and extracting hemicellulose. In this study, three ILs, namely 1-butyl-3-methylimidazolium chloride (BmimCl), 1-butyl-3-methylimidazolium bromide (BmimBr), and 1-butyl-3-methylimidazolium iodide (Bmiml), were used as solvents to dissolve bamboo hemicellulose over the temperature range of $80^{\circ} \mathrm{C}$ to $150{ }^{\circ} \mathrm{C}$. Representative hemicellulose with a solubility higher than $9.0 \mathrm{~g} / 100 \mathrm{~g} \mathrm{IL}$ was regenerated and characterized. The interaction between the hemicellulose and ILs was evaluated using carbon-13 nuclear magnetic resonance. The results showed that the solubility of hemicellulose in the ILs was in the following order: $\mathrm{BmimCl}>$ $\mathrm{BmimBr}>\mathrm{Bmiml}$. Though moderate degradation of the hemicellulose possibly occurred during dissolution, the main chain of the hemicellulose was almost unchanged. The enhanced solubility of the hemicellulose was because of the formation of hydrogen bonds between the hydroxyl proton of the hemicellulose and anion of the ILs.
\end{abstract}

Keywords: Hemicellulose; Ionic liquid; Solubility; Hydrogen bond; NMR technique; Interaction

Contact information: a: Engineering Research Center of Biomass Conversion, Ministry of Education, Nanchang University, Nanchang, Jiangxi 330047, P R. China; b: School of Materials Science and Engineering, Nanchang University, Nanchang, Jiangxi 330031, P R. China; c: State Key Laboratory of Food Science and Technology, Nanchang University, Nanchang, Jiangxi 330031, P R. China; d: School of Materials Science and Engineering, East China University of Science and Technology, Shanghai 200237, P R. China; $e$ : Center of Analysis and Testing, Nanchang University, Nanchang, Jiangxi 330047, P R. China;

* Corresponding author: penghong@ncu.edu.cn

\section{INTRODUCTION}

Utilization of renewable lignocellulosic biomass has been paid considerable attention because of the deteriorating environment and energy crisis (Castro et al. 2017; López-Linares et al.2018; Mazar et al. 2018). Lignocellulosic biomass is mainly composed of hemicellulose, cellulose, and lignin. In plant cell walls, hemicellulose is linked with lignin through covalent bonds, and the combined chemical structures are known as lignincarbohydrate complexes (Deshpande et al. 2018). Meanwhile, hydrogen bonds are assumed to cause the association between hemicellulose and cellulose (Lodish et al. 2000). Hemicellulose is a heterogeneous polysaccharide consisting of xylose, arabinose, galactose, glucose, mannose, and uronic acid (Liu et al. 2018; Santos et al. 2018). Hemicellulose can be used as a raw material to produce fuel (Castro et al. 2017), fine chemicals (Mazar et al. 2018), functional food ingredients (López-Linares et al. 2018), and bio-based materials (Du et al. 2018). Hence, given their economic value, hemicelluloses should be pre-extracted prior to value-added utilization of these polysaccharides. A traditional method with an alkaline or acidic extractant is usually adopted to obtain 
hemicellulose (Hutterer et al. 2016; Stoffel et al. 2017; Liu et al. 2018). However, this technique commonly results in environmental problems and hemicellulose degradation.

Ionic liquids (ILs), which are generally composed of ion-pairs with anions and cations, have low melting points and volatilities, negligible vapor pressures, and excellent thermal stabilities (Brandt-Talbot et al. 2017; Cao et al. 2017; Mohtar et al. 2017). Also, ILs can be recovered and reused, which are characteristics that are advantageous for reducing the economic cost and environmental pressure (Yang et al. 2013). Compared with alkaline and acidic extractants, ILs have been shown to have broad prospects for dissolution and fractionation of lignocellulosic biomass (Eisenhuber et al. 2013; Arni 2018; Magnin et al. 2018). However, deep understanding of the interaction between ILs and the three main components of lignocellulose is necessary to explore efficient utilization of ILs in the dissolution and pretreatment of lignocellulosic biomass. To date, numerous studies have been conducted on the dissolution mechanisms of cellulose and lignin in ILs (Vitz et al. 2009; Xu et al. 2010; Ji et al. 2012; Lu et al. 2014; Xu et al. 2014; Hart et al. 2015; Moyer et al. 2018). Nevertheless, the dissolution behavior of hemicellulose in ILs has rarely been reported (Zhao et al. 2010; Froschauer et al. 2012; Payal et al. 2012; Bylin et al. 2014; Castro et al. 2015). Bylin et al. (2014) showed that, although cellulose and xylan can be efficiently dissolved in a two-component solvent system consisting of the IL 1ethyl-3-methylimidazolium acetate and co-solvent 1-methylimidazole, xylan solvation was slower than cellulose solvation because of the diversity of xylans. Froschauer et al. (2012) reported that selective fractionation of xylan from hemicellulose-rich pulp could be achieved if the hydrogen-bond basicity ( $\beta$ value) of the IL 1-butyl-3-methylimidazolium dimethyl phosphate decreased. The solubility of xylan can be described well using different parameters for the $\beta$ value (Froschauer et al. 2012). Density functional theory calculations predict that inter- and intramolecular hydrogen bonding play an important role in the dissolution of xylan, which was chosen as a model for hemicellulose, in the IL 1,3dimethylimidazolium acetate (Payal et al. 2012). Simulations of molecular dynamics have suggested that the strong interaction between the IL 1-allyl-3-methylimidazolium formate and hemicellulose is an important factor to enhance the solubility of lignocellulosic biomass in the IL (Moyer et al. 2018). Overall, no clear dissolution behavior has been determined for hemicellulose in ILs.

In this study, the dissolution of bamboo hemicellulose in imidazolium halide-based ILs, namely 1-butyl-3-methylimidazolium chloride (BmimCl), 1-butyl-3-methylimidazolium bromide (BmimBr), and 1-butyl-3-methylimidazolium iodide (BmimI), was evaluated. A set of comparative experiments were performed to elucidate the influence of the anionic structure on dissolution. The regenerated hemicellulose were analyzed by gel permeation chromatography (GPC), gas chromatography-mass spectrometry (GC-MS), Fourier transform infrared spectroscopy (FT-IR), and thermogravimetric (TG) analysis to examine their structural and thermal properties. Finally, the interaction between the hemicellulose and ILs was investigated by carbon-13 nuclear magnetic resonance $\left({ }^{13} \mathrm{C}\right.$ NMR) to determine the possible dissolution mechanism.

\section{EXPERIMENTAL}

\section{Materials}

Bamboo (Phyllostachys pubescens Mazel) was obtained from a local farm in Nanchang (China). Prior to hemicellulose extraction, the fully dry bamboo stem was cut 
into small pieces, ground to pass through a 40-mesh screen, followed by a 100-mesh screen, and dried further in an oven at $50{ }^{\circ} \mathrm{C}$ for $12 \mathrm{~h}$. The ILs BmimCl (>99\%), BmimBr (> 99\%), and BmimI (> 99\%) were purchased from Shanghai Chengjie Chem. Co., Ltd. (Shanghai, China) and dried further in a vacuum oven at $150{ }^{\circ} \mathrm{C}$ before use. The water contents in $\mathrm{BmimCl}, \mathrm{BmimBr}$, and BmimI, which were measured using the Karl-Fischer method, were 1857, 2130, and $2254 \mathrm{ppm}$, respectively. The schematic structures and numbering of these three ILs are displayed in Fig. 1. Trimethyl chlorosilane (TMS) (99\%) and 1,1,1,3,3,3hexamethyldisilazane (HMDS) (> 99\%) were purchased from J\&K Scientific Co., Ltd. (Beijing, China). Acetic acid (> 99.8\%), 95\% ethanol, DMSO-d 6 (> 99.9\%), and sodium chlorite $\left(\mathrm{NaClO}_{2}\right)$ (> 98\%) were purchased from Shanghai Aladdin Chem. Co., Ltd. (Shanghai, China). Sodium hydroxide (>96\%), petroleum ether $(>90 \%)$, trifluoro acetic acid (> 99\%), and anhydrous ethanol (> 99\%) were purchased from Tianjin Damao Chem. Co., Ltd. (Tianjin, China). Neutral sugar standards, including xylose (>99\%), arabinose (> $99 \%)$, ribose $(>96 \%)$, glucose $(>99 \%)$, mannose $(>99 \%)$, and galactose $(>95 \%)$, were obtained from Tianjin HEOWNS Biochem. Tech. Co., Ltd. (Tianjin, China). Distilled and deionized water was used as the solvent to prepare all of the reagent solutions.

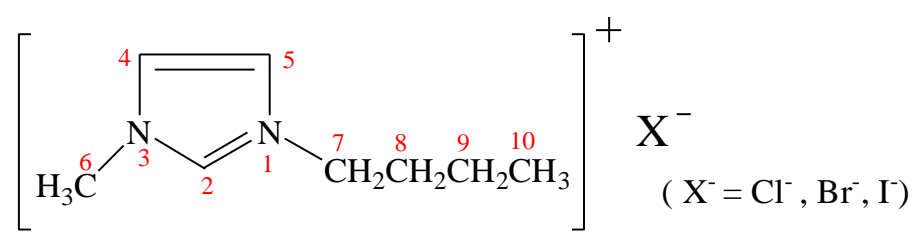

Fig. 1. Schematic structures and numbering of the ILS

\section{Methods}

Preparation of the bamboo hemicellulose

Bamboo hemicellulose was prepared according to the method previously reported by Peng et al. (2012) with some modifications.

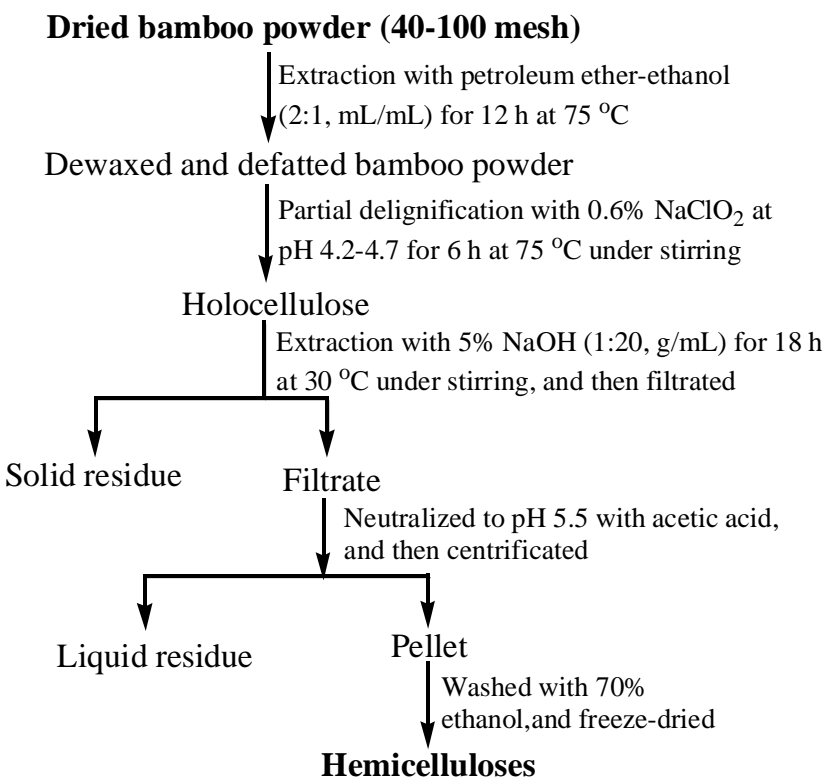

Fig. 2. Process for separation of hemicellulose from bamboo 
The extraction scheme is illustrated in Fig. 2. First, the dried bamboo powder was dewaxed and defatted with petroleum ether-ethanol $(2: 1, \mathrm{~mL} / \mathrm{mL})$ for $12 \mathrm{~h}$ at $75{ }^{\circ} \mathrm{C}$ in a Soxhlet extractor. Second, the dewaxed and defatted bamboo powder was partially delignified with $0.6 \% \mathrm{NaClO}_{2}(\mathrm{pH}=4.2$ to 4.7$)$ for $6 \mathrm{~h}$ at $75^{\circ} \mathrm{C}$ under stirring, and the ratio of dry matter-to-liquor was 1:10 (w/v, g/mL). The obtained holocellulose was further treated with $5 \% \mathrm{NaOH}$ at $30{ }^{\circ} \mathrm{C}$ for $18 \mathrm{~h}$, and the ratio of dry matter-to-liquor was 1:20 $(\mathrm{w} / \mathrm{v}, \mathrm{g} / \mathrm{mL})$. After filtration, the alkaline filtrate containing solubilized hemicellulose was adjusted to a $\mathrm{pH}$ of 5.5 using acetic acid, and the formed pellet was washed with $70 \%$ ethanol and then freeze-dried. The final bamboo hemicellulose powder obtained was stored in a desiccator before use.

\section{Dissolution of the bamboo hemicellulose in the ILs}

For a typical solubility measurement, the IL (10 g) was sealed in a round-bottomed flask immersed in an oil bath (DF-101S, Gongyi Yingyu Instrument Factory, Zhengzhou, China). After the IL was heated to the designated temperature, completely dry bamboo hemicellulose powder $(0.5 \mathrm{wt} . \%)$ was added. The mixture was heated at a given temperature for $1 \mathrm{~h}$ with continuous magnetic stirring at $200 \mathrm{rpm}$. Then, additional hemicellulose (0.5 wt.\% per time) was gradually added until the IL solution became optically unclear under a fluorescence microscope (LWD200-37FT, Shanghai Dimensional Measurement Factory, Shanghai, China). The solubility of the bamboo hemicellulose at a given temperature was calculated based on the amount of IL used and total amount of hemicellulose added. This parameter was expressed as the weight of the hemicellulose per $100 \mathrm{~g}$ of IL (g/100 g IL). The solubility of the bamboo hemicellulose in the three ILs were measured over the temperature range of $80^{\circ} \mathrm{C}$ to $150{ }^{\circ} \mathrm{C}$ with an interval of $10^{\circ} \mathrm{C}$. All the measurements were performed in triplicate.

\section{Regeneration of the bamboo hemicellulose}

The bamboo hemicellulose was regenerated from the ILs by adding anti-solvent ethanol to the saturated mixture of IL and hemicellulose. Three volumes of $95 \%$ ethanol were added to the saturated mixture, and then the mixture was allowed to settle for $12 \mathrm{~h}$. The precipitated hemicellulose was collected by centrifugation at $4000 \mathrm{rpm}$ and washed repeatedly with $95 \%$ ethanol to completely remove the IL contaminant. Finally, the regenerated hemicellulose was freeze-dried and used for further characterization. After removing the anti-solvent ethanol, the ILs were recovered. The yield of regenerated hemicellulose was calculated based on the weight ratio of recovered hemicellulose to the totally dissolved hemicellulose.

\section{Characterization of the bamboo hemicellulose}

The weight-average molecular weight $\left(M_{\mathrm{w}}\right)$ of the original and regenerated hemicellulose was measured by GPC on a 1200 Series chromatograph (Agilent, California, USA) with a PL aquagel-OH MIXED column $(7.5 \mathrm{~mm} \times 300 \mathrm{~mm})$. Sodium phosphate buffer (containing 0.02 wt.\% $0.005 \mathrm{M} \mathrm{NaN}_{3} ; \mathrm{pH}=7.5$ ) was used as an eluent and solvent for the hemicellulose. The column was eluted at $0.5 \mathrm{~mL} / \mathrm{min}$ and $30{ }^{\circ} \mathrm{C}$. The injection volume of the sample was $100 \mu \mathrm{L}$. Prior to injection, the hemicellulose was dissolved in $0.005 \mathrm{M}$ sodium phosphate buffer $(0.1 \mathrm{wt} . \%)$, and then filtered through a $0.45-\mu \mathrm{m}$ microporous cellulose membrane. The eluent was monitored with a refractive index detector (GPC RID) (BI-DNDC, BIC, New York, USA). Simultaneously, dextrans (Sigma- 
Aldrich, Buchs, Switzerland) with $M_{\mathrm{w}}$ values of 1270 Da, $5220 \mathrm{Da}, 11600 \mathrm{Da}, 23800 \mathrm{Da}$, and $48600 \mathrm{Da}$ were used as $M_{\mathrm{w}}$ standards.

The neutral sugar compositions of the original and regenerated hemicellulose were determined according to the method previously reported by Peng et al. (2012) with some modifications. Generally, $20 \mathrm{mg}$ of the hemicellulose sample was hydrolyzed using $3.0 \mathrm{M}$ trifluoro acetic acid (TFA) at $120^{\circ} \mathrm{C}$ for $3 \mathrm{~h}$ in a $30-\mathrm{mL}$ pressure vessel. The hydrolysates were then diluted with anhydrous ethanol, and the TFA was removed using a rotary vacuum evaporator at $55{ }^{\circ} \mathrm{C}$. Anhydrous ethanol was then added to the solids, followed by reevaporation. This procedure was repeated several times, until the hydrolysates obtained were neutral. The fully freeze-dried hydrolysate was dissolved in anhydrous pyridine (1.2 $\mathrm{mL}$ ) in a tube. After heating to $50{ }^{\circ} \mathrm{C}, 0.8 \mathrm{~mL}$ of TMS and $1.6 \mathrm{~mL}$ of HMDS were added. The tube was heated for $60 \mathrm{~min}$ at $50{ }^{\circ} \mathrm{C}$ after sealing, then cooled and centrifuged. The supernatant of the silylated compounds was measured using GC-MS (7890B-7000D, Agilent) with a HP-PONA capillary column $(50 \mathrm{~m} \times 200 \mu \mathrm{m} \times 0.5 \mu \mathrm{m})$ (Agilent). One microliter of the sample was automatically injected. The oven temperature program was as follows: (1) the initial temperature of $45{ }^{\circ} \mathrm{C}$ was held for $5 \mathrm{~min}$; (2) the temperature increased from $45{ }^{\circ} \mathrm{C}$ to $180{ }^{\circ} \mathrm{C}$ at $5{ }^{\circ} \mathrm{C} / \mathrm{min}$ and was held at $180{ }^{\circ} \mathrm{C}$ for $2 \mathrm{~min}$; and (3) the temperature increased from $180{ }^{\circ} \mathrm{C}$ to $280{ }^{\circ} \mathrm{C}$ at $8{ }^{\circ} \mathrm{C} / \mathrm{min}$ and was then held at $280{ }^{\circ} \mathrm{C}$ for 3 min. Highly purified He with a flow rate of $15 \mathrm{~mL} / \mathrm{min}$ was used as a carrier gas with a split ratio of 50:1. The mass spectra were obtained by electron impact ionization at $70 \mathrm{eV}$. Simultaneously, six neutral sugar standards, including xylose, arabinose, ribose, glucose, mannose, and galactose, were converted to their TMS derivatives and analyzed using GCMS to more accurately determine the neutral sugar compositions of the hemicellulose samples.

The FT-IR spectra of the original and regenerated hemicellulose was recorded on a Nicolet iS5 FT-IR spectrophotometer (Thermo Fisher Scientific, Massachusetts, USA) with $\mathrm{KBr}$ pellets over the range of $4000 \mathrm{~cm}^{-1}$ to $400 \mathrm{~cm}^{-1}$ at a $2 \mathrm{~cm}^{-1}$ resolution.

The thermal properties of the original and regenerated hemicellulose was evaluated using a TGA 4000 (Perkin Elmer, Massachusetts, USA). The samples were heated from 30 ${ }^{\circ} \mathrm{C}$ to $600{ }^{\circ} \mathrm{C}$ at a rate of $10{ }^{\circ} \mathrm{C} / \mathrm{min}$ under a nitrogen atmosphere with a flow rate of 50 $\mathrm{mL} / \mathrm{min}$. For the analysis, $10.1 \mathrm{mg}$ to $16.9 \mathrm{mg}$ of hemicellulose was used.

\section{${ }^{13}$ C NMR analysis of the interaction between the ILs and hemicellulose}

The ${ }^{13} \mathrm{C}$ NMR spectra were recorded on a Bruker Avance $600 \mathrm{MHz}$ spectrometer (Karlsruhe, Germany) with a $5 \mathrm{~mm}-\mathrm{PABBO}$ probe at $25^{\circ} \mathrm{C}$. Hemicellulose $(20 \mathrm{mg})$ was added to a NMR tube with $0.5 \mathrm{~mL}$ of DMSO- $\mathrm{d}_{6}$ and $200 \mathrm{mg}$ of IL. Tetramethylsilane was used as the internal standard. Prior to the NMR measurement, the hemicellulose should be completely dissolved. As a control, $20 \mathrm{mg}$ of the original hemicellulose and $200 \mathrm{mg}$ of the IL were separately dissolved in $0.5 \mathrm{~mL}$ of DMSO- $\mathrm{d}_{6}$. The ${ }^{13} \mathrm{C}$ NMR spectra were recorded at $100.6 \mathrm{MHz}$.

\section{RESULTS AND DISCUSSION}

\section{Solubility of the Bamboo Hemicellulose in the ILs}

The typical solubilization of the bamboo hemicellulose in $\mathrm{BmimCl}$ at $100{ }^{\circ} \mathrm{C}$ under a fluorescence microscope is shown in Fig. 3. No hemicellulose particles were observed when the IL solution was not saturated (Fig. 3a). However, the microscope results showed 
several hemicellulose particles when the IL solution was saturated (Fig. 3b). Furthermore, more undissolved hemicellulose particles were present after more hemicellulose was added to the saturated solution (Fig. 3c). Thus, the saturated state of the hemicellulose in the ILs could be evaluated using the microscope images.
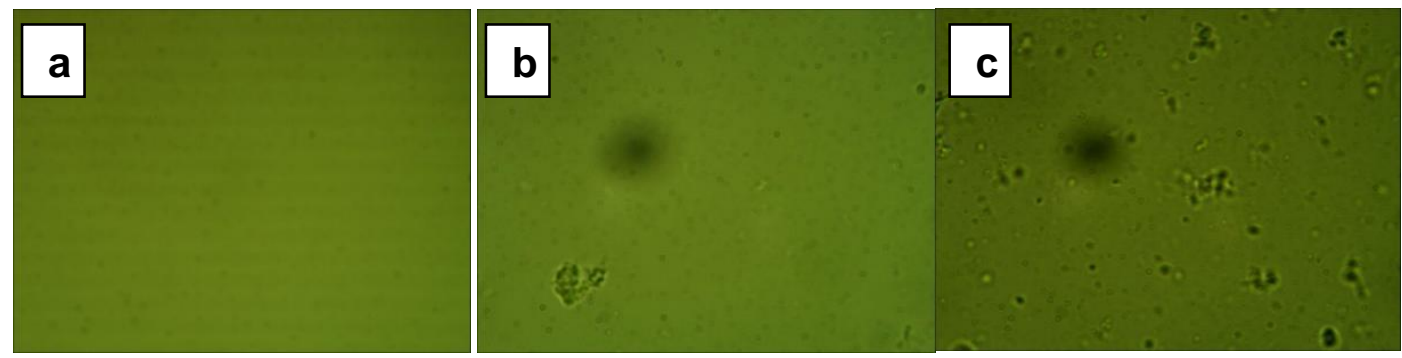

Fig. 3. Solubilization of the hemicellulose in $\mathrm{BmimCl}$ at $100^{\circ} \mathrm{C}(400 \mathrm{x}$ magnification): (a) unsaturated, (b) saturated, and (c) oversaturated

The solubility data of the bamboo hemicellulose in $\mathrm{BmimCl}, \mathrm{BmimBr}$, and $\mathrm{BmimI}$ from $80{ }^{\circ} \mathrm{C}$ to $150{ }^{\circ} \mathrm{C}$ are listed in Table 1 . The solubility of the hemicellulose at a given temperature decreased in the following order: $\mathrm{BmimCl}>\mathrm{BmimBr}>\mathrm{BmimI}$. This solubility order was in accordance with the literature concerning the solubility of cellulose in BmimCl, BmimBr, and BmimI (Vitz et al. 2009; Zhao et al. 2013). Considering that the same cation was present in each case, this result suggested that the anionic structure of the ILs plays a key role in the solubility of hemicellulose. According to Lungwitz and Spange (2008), the Kamlet-Taft $\beta$ parameter values of $\mathrm{Cl}^{-}, \mathrm{Br}^{-}$, and $\mathrm{I}^{-}$are 0.94, 0.87, and 0.75, respectively (Table 1). Also, the Kamlet-Taft $\beta$ parameter can be used to evaluate the hydrogen bond-accepting ability of anions in ILs (Lungwitz and Spange 2008; Xu et al. 2010; Chen et al. 2011; Froschauer et al. 2012; Magnin et al. 2018). Thus, the hydrogen bond-accepting ability of $\mathrm{Cl}^{-}, \mathrm{Br}^{-}$, and $\mathrm{I}^{-}$is in the following order: $\mathrm{Cl}^{-}>\mathrm{Br}^{-}>\mathrm{I}^{-}$. The solubility result of hemicellulose was in accordance with the hydrogen bond-accepting ability of the anions in the three ILs. Therefore, it could be concluded that the hydrogen bond-accepting ability of an anion plays an important role in the solubility of hemicellulose. The formation of hydrogen bonds between the anions in the ILs and the proton in the hydroxyl groups from the hemicellulose resulted in the disruption of intraand intermolecular hydrogen bonds in the hemicellulose and an increase in the solubility of hemicellulose in the ILs (Xu et al. 2010; Chen et al. 2011; Payal et al. 2012; Froschauer et al. 2012; Lu et al. 2014). The $\mathrm{Cl}^{-}$favored attacking the hydroxyl proton in the hemicellulose, which led to more hemicellulose that could be dissolved in $\mathrm{BmimCl}$.

Moreover, the solubility of the hemicellulose in the ILs increased with the temperature and then decreased with a further increase in the temperature. A possible reason was that the hydrogen bonds formed between the hemicellulose molecules and IL were unstable and partially disrupted at higher temperatures. Hence, an appropriate temperature should be selected for dissolving hemicellulose. The highest solubility of the hemicellulose in $\mathrm{BmimCl}$ was $18.8 \mathrm{~g} / 100 \mathrm{~g} \mathrm{IL}$ at $120^{\circ} \mathrm{C}$, and the solubility obtained at 110 ${ }^{\circ} \mathrm{C}$ was $16.6 \mathrm{~g} / 100 \mathrm{~g}$ IL. The solubility of bamboo hemicellulose in $\mathrm{BmimCl}$ at $110{ }^{\circ} \mathrm{C}$ was higher than that of xylan from oat spelt (7 g/100 g IL) (Zhao et al. 2010). However, the highest solubilities of the hemicellulose in BmimBr and BmimI were $10.0 \mathrm{~g} / 100 \mathrm{~g}$ IL and $0.6 \mathrm{~g} / 100 \mathrm{~g} \mathrm{IL}$ at $100{ }^{\circ} \mathrm{C}$ and $120{ }^{\circ} \mathrm{C}$, respectively, which were lower than that in $\mathrm{BmimCl}$. This indicated that $\mathrm{BmimBr}$ and $\mathrm{BmimI}$ were not as good solvents for hemicellulose. This 
result was in accordance with the results for cellulose in halogen anion-containing imidazolium ILs (Zavrel et al. 2009).

Table 1. Solubilities of the Hemicellulose in the ILs at Different Temperatures

\begin{tabular}{|c|c|c|c|c|c|c|c|c|c|}
\hline \multirow[b]{2}{*}{ IL } & \multirow[b]{2}{*}{$\beta$} & \multicolumn{8}{|c|}{ Solubility $(\mathrm{g} / 100 \mathrm{~g} \mathrm{IL})$} \\
\hline & & $80^{\circ} \mathrm{C}$ & $90^{\circ} \mathrm{C}$ & $100^{\circ} \mathrm{C}$ & $110^{\circ} \mathrm{C}$ & $120^{\circ} \mathrm{C}$ & $130^{\circ} \mathrm{C}$ & $140^{\circ} \mathrm{C}$ & $150^{\circ} \mathrm{C}$ \\
\hline \multirow{2}{*}{$\mathrm{BmimCl}$} & \multirow{2}{*}{$0.94^{a}$} & $2.5 \pm$ & $9.2 \pm$ & $12.8 \pm$ & $16.6 \pm$ & $18.8 \pm$ & $11.0 \pm$ & $3.0 \pm$ & $2.7 \pm$ \\
\hline & & 0.1 & 0.1 & 0.1 & 0.0 & 0.1 & 0.0 & 0.1 & 0.1 \\
\hline \multirow{2}{*}{$\mathrm{BmimBr}$} & \multirow{2}{*}{$0.87^{a}$} & $0.6 \pm$ & $3.0 \pm$ & $10.0 \pm$ & $1.8 \pm$ & $2.0 \pm$ & $2.6 \pm$ & $2.5 \pm$ & $2.0 \pm$ \\
\hline & & 0.0 & 0.1 & 0.1 & 0.1 & 0.1 & 0.2 & 0.1 & 0.0 \\
\hline \multirow{2}{*}{ Bmiml } & \multirow{2}{*}{0.75} & $0.1 \pm$ & $0.1 \pm$ & $0.2 \pm$ & $0.6 \pm$ & $0.6 \pm$ & $0.4 \pm$ & $0.4 \pm$ & $0.4 \pm$ \\
\hline & & 0.0 & 0.0 & 0.0 & 0.0 & 0.0 & 0.1 & 0.0 & 0.0 \\
\hline
\end{tabular}

a Measured at the melting point

\section{Characterization of the Regenerated Hemicellulose}

Representative hemicellulose samples with a solubility higher than $9.00 \mathrm{~g} / 100 \mathrm{~g} \mathrm{IL}$ in $\mathrm{BmimCl}$ and $\mathrm{BmimBr}$ were regenerated from the ILs using ethanol. The regenerated hemicellulose fractions from $\mathrm{BmimCl}$ were labeled $\mathrm{RH}_{1}, \mathrm{RH}_{2}, \mathrm{RH}_{3}, \mathrm{RH}_{4}$, and $\mathrm{RH}_{5}$, which corresponded to the dissolution temperatures of $90{ }^{\circ} \mathrm{C}, 100{ }^{\circ} \mathrm{C}, 110{ }^{\circ} \mathrm{C}, 120{ }^{\circ} \mathrm{C}$, and 130 ${ }^{\circ} \mathrm{C}$, respectively. The sample regenerated from $\mathrm{BmimBr}$ at a dissolution temperature of 100 ${ }^{\circ} \mathrm{C}$ was marked $\mathrm{RH}_{6}$. Fractions $\mathrm{RH}_{1}$ through $\mathrm{RH}_{6}$ were characterized and compared with the original hemicellulose.

\section{Yield and molecular weight distribution}

The yields of regenerated hemicellulose are provided in Table 2 . Only $64 \%$ to $85 \%$ of the hemicellulose could be recovered from $\mathrm{BmimCl}$ and $\mathrm{BmimBr}$ by adding three volumes of ethanol. This phenomenon may have been caused by residual low-molecular weight hemicellulose kept in the IL solutions.

The molecular weight distributions for the original and regenerated hemicellulose were determined by GPC to evaluate the degradation degree during dissolution, and the results are shown in Table 2 . The weight-average molecular weights $\left(M_{\mathrm{w}}\right)$, number-average molecular weight $\left(M_{\mathrm{n}}\right)$, and polydispersity $\left(M_{\mathrm{w}} / M_{\mathrm{n}}\right)$ of the original hemicellulose were $50,200 \mathrm{~g} / \mathrm{mol}, 398,00 \mathrm{~g} / \mathrm{mol}$, and 1.262 , respectively. The $M_{\mathrm{w}}$ values for the hemicellulose regenerated from $\mathrm{BmimCl}$ and $\mathrm{BmimBr}$ were in the range of $49,300 \mathrm{~g} / \mathrm{mol}$ to $50,100 \mathrm{~g} / \mathrm{mol}$, which were close to that of the original hemicellulose. This result confirmed that almost no depolymerization occurred during dissolution of the bamboo hemicellulose in the ILs.

Table 2. Weight-average and Number-average Molecular Weights and Polydispersity of the Original and Regenerated Hemicellulose

\begin{tabular}{|c|c|c|c|c|c|c|c|}
\hline & \multicolumn{7}{|c|}{ Hemicellulose } \\
\cline { 2 - 8 } & $\mathrm{OH}_{0}$ & $\mathrm{RH}_{1}$ & $\mathrm{RH}_{2}$ & $\mathrm{RH}_{3}$ & $\mathrm{RH}_{4}$ & $\mathrm{RH}_{5}$ & $\mathrm{RH}_{6}$ \\
\hline Yield (\%) & - & 64 & 72 & 74 & 85 & 72 & 76 \\
\hline $\mathrm{M}_{\mathrm{w}}(\mathrm{g} / \mathrm{mol})$ & 50,200 & 49,900 & 49,400 & 49,400 & 49,700 & 49,300 & 50,100 \\
\hline $\mathrm{M}_{\mathrm{n}}(\mathrm{g} / \mathrm{mol})$ & 39,800 & 47,000 & 45,700 & 44,400 & 45,300 & 46,600 & 46,900 \\
\hline $\mathrm{M}_{\mathrm{w}} / \mathrm{M}_{\mathrm{n}}$ & 1.262 & 1.060 & 1.088 & 1.074 & 1.098 & 1.057 & 1.068 \\
\hline
\end{tabular}

$\mathrm{OH}_{0}$ - Original hemicellulose 
Meanwhile, all of the regenerated hemicellulose resulted in a markedly smaller polydispersity (1.002 to 1.213$)$ compared with the original hemicellulose $\left(M_{\mathrm{w}} / M_{\mathrm{n}}=1.262\right)$. This event indicated that the regenerated hemicellulose showed a higher molecular homogeneity than the original hemicellulose. The decrease in the polydispersity may have resulted from the unrecoverable low-molecular weight hemicellulose fraction.

\section{Neutral sugar composition}

The neutral sugar contents in the regenerated and original hemicellulose are shown in Table 3. The original hemicellulose was rich in xylose $(87.6 \%)$ and arabinose $(8.7 \%)$, and these components accounted for $96.3 \%$. Compared with xylose, the relative arabinose content was lower. Xylose (ranging from $72.4 \%$ to $88.7 \%$ ) and arabinose (ranging from $9.4 \%$ to $19.0 \%$ ) were the dominant component sugars in all of the regenerated hemicellulose samples. Moreover, the total content of xylose and arabinose in all of the regenerated hemicellulose accounted for $89.5 \%$ to $98.1 \%$, which was similar to that of the original hemicellulose. The relative contents of glucose in the regenerated and original hemicellulose ranged from $1.7 \%$ to $9.7 \%$, which were lower than for arabinose. Meanwhile, mannose and galactose were identified in minor quantities in the original and regenerated hemicellulose. These results further suggested that the main chain of the hemicellulose $\left(\mathrm{RH}_{1}\right.$ to $\left.\mathrm{RH}_{6}\right)$ was not damaged by the ILs during dissolution, and the main component of the hemicellulose was almost unchanged.

Table 3. Neutral Sugar Contents in the Regenerated and Original Hemicellulose

\begin{tabular}{|c|c|c|c|c|c|c|c|}
\hline \multirow{2}{*}{ Sugar } & \multicolumn{7}{|c|}{ Hemicellulose $^{\mathrm{a}}$} \\
\cline { 2 - 8 } & $\mathrm{OH}_{0}$ & $\mathrm{RH}_{1}$ & $\mathrm{RH}_{2}$ & $\mathrm{RH}_{3}$ & $\mathrm{RH}_{4}$ & $\mathrm{RH}_{5}$ & $\mathrm{RH}_{6}$ \\
\hline Xylose (\%) & 87.6 & 88.7 & 76.0 & 73.5 & 78.3 & 72.4 & 73.8 \\
\hline Arabinose (\%) & 8.7 & 9.4 & 13.7 & 16.0 & 13.7 & 19.0 & 16.7 \\
\hline Mannose (\%) & 0.7 & $\mathrm{n} . \mathrm{d}$ & 0.1 & 0.6 & 0.4 & n.d & 0.7 \\
\hline Galactose (\%) & 0.9 & 0.1 & 0.5 & 1.9 & 0.9 & 2.0 & 1.0 \\
\hline Glucose (\%) & 2.1 & 1.7 & 9.7 & 8.1 & 6.6 & 6.6 & 7.8 \\
\hline $\begin{array}{c}\text { Xylose + } \\
\text { Arabinose (\%) }\end{array}$ & 96.3 & 98.1 & 89.7 & 89.5 & 92.0 & 91.4 & 90.5 \\
\hline
\end{tabular}

a Corresponding to the hemicellulosic fractions in Table 2; n.d - not determined

\section{FT-IR spectral analysis}

The FT-IR spectra of the original and regenerated hemicellulose from $\mathrm{BmimCl}$ and BmimBr are shown in Fig. 4a. The FT-IR spectra of the regenerated and original hemicellulose were similar, which indicated that the main chain of regenerated hemicellulose $\left(\mathrm{RH}_{1}\right.$ to $\left.\mathrm{RH}_{6}\right)$ was not destroyed by the ILs during dissolution. Characteristic peaks associated with hemicellulose were observed at $3433 \mathrm{~cm}^{-1}$ (OH stretching), 2934 $\mathrm{cm}^{-1}$ (C-H stretching of $\left.-\mathrm{CH}_{2}-\right), 1420 \mathrm{~cm}^{-1}$ (- $\mathrm{CH}_{2}$ - deformation), $1378 \mathrm{~cm}^{-1}$ (C-H bending vibration), $1167 \mathrm{~cm}^{-1}$ (C-O-C and C-C stretching), and $1250 \mathrm{~cm}^{-1}$ and $1050 \mathrm{~cm}^{-1}$ (C-O stretching or C-OH bending) (Kačuráková et al. 1994; Xu et al. 2010; Peng et al. 2011; Peng et al. 2012). The characteristic FT-IR peak of the adsorbed water was at approximately $1640 \mathrm{~cm}^{-1}$. The weak peaks at $1510 \mathrm{~cm}^{-1}$ were attributed to aromatic skeletal vibration in the associated lignin. This result implied that the hemicellulose was slightly contaminated with minimal amounts of bound lignin (Peng et al. 2012). The bands at $1568 \mathrm{~cm}^{-1}$ corresponded to symmetrical stretching of carboxylic anions (Peng et al. 2011). Additionally, the weak band at $987 \mathrm{~cm}^{-1}$ indicated the presence of arabinose 
attached at the O-3 position of the xylopyransyl constituents (Ebringerová et al. 1992). The sharp band at $897 \mathrm{~cm}^{-1}$ was assigned to the $\mathrm{C}-1$ group frequency or ring frequency, which was characteristic of $\beta$-glycosidic linkages between sugar units (Gupta et al. 1987). From the neutral sugar composition results (Table 3) and FT-IR spectra (Fig. 4a), it was concluded that both the original and regenerated hemicellulose mainly consisted of arabinoxylans (Peng et al. 2012).

\section{Thermal stability analysis}

The thermal stabilities of the original and regenerated hemicellulose underwent TG analysis, and the results are given in Fig. $4 \mathrm{~b}$ and Table 4 . The regenerated hemicellulose exhibited a slightly higher initial temperature $\left(220{ }^{\circ} \mathrm{C}\right.$ to $\left.232{ }^{\circ} \mathrm{C}\right)$ for fast decomposition compared with the original hemicellulose $\left(203{ }^{\circ} \mathrm{C}\right)$. Also, in the fast pyrolysis stage, the weight losses were $44.8 \%, 48.4 \%, 50.4 \%, 50.4 \%, 49.3 \%, 49.9 \%$, and $47.8 \%$ for the original hemicellulose $\left(\mathrm{OH}_{0}\right), \mathrm{RH}_{1}, \mathrm{RH}_{2}, \mathrm{RH}_{3}, \mathrm{RH}_{4}, \mathrm{RH}_{5}$, and $\mathrm{RH}_{6}$, respectively (Table 4). The regenerated hemicellulose showed slightly faster pyrolysis rates compared with the original hemicellulose in the fast pyrolysis stage. Meanwhile, the regenerated hemicellulose showed slightly lower residue yields at $600{ }^{\circ} \mathrm{C}$ ( $26.2 \%$ to $\left.29.9 \%\right)$ compared with the original hemicellulose $(33.4 \%)$ (Table 4$)$. These results indicated that the thermal stabilities of the regenerated hemicellulose were slightly weakened, which may have been caused by disruption of the hydrogen bonds by the ILs. This phenomenon loosened the hemicellulose and decreased the thermal stability, which led to higher weight losses in the fast pyrolysis stage and lower residue yields at the final temperature of $600{ }^{\circ} \mathrm{C}$.
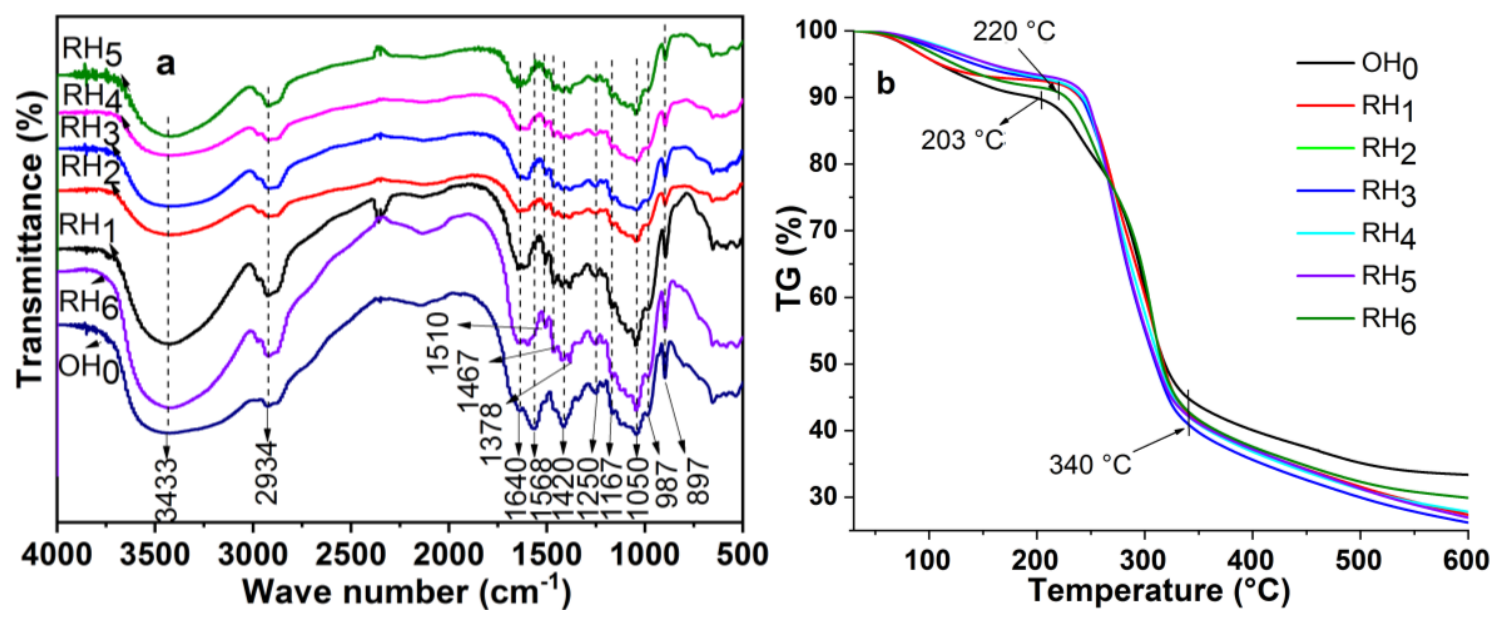

Fig. 4. FT-IR spectra (a) and TG curves (b) of the original $\left(\mathrm{OH}_{0}\right)$ and regenerated hemicellulose $\left(\mathrm{RH}_{1}-\mathrm{RH}_{6}\right)$

Table 4. Thermal Parameters for the Original and Regenerated Hemicellulose

\begin{tabular}{|c|c|c|c|}
\hline Hemicellulose & $\begin{array}{c}\text { Temperature Range for } \\
\text { Fast Pyrolysis }\left({ }^{\circ} \mathrm{C}\right)\end{array}$ & $\begin{array}{c}\text { Weight Loss at the Fast } \\
\text { Pyrolysis Stage }(\%)\end{array}$ & $\begin{array}{c}\text { Residue at } \\
600{ }^{\circ} \mathrm{C}(\%)\end{array}$ \\
\hline $\mathrm{OH}_{0}$ & $203-340$ & 44.8 & 33.4 \\
\hline $\mathrm{RH}_{1}$ & $220-340$ & 48.4 & 27.4 \\
\hline $\mathrm{RH}_{2}$ & $220-340$ & 50.4 & 26.2 \\
\hline $\mathrm{RH}_{3}$ & $220-340$ & 50.4 & 26.2 \\
\hline $\mathrm{RH}_{4}$ & $220-340$ & 49.3 & 27.8 \\
\hline $\mathrm{RH}_{5}$ & $220-340$ & 49.9 & 26.9 \\
\hline $\mathrm{RH}_{6}$ & $220-340$ & 47.8 & 29.9 \\
\hline
\end{tabular}




\section{Interaction Between the ILs and Hemicellulose}

The interaction between the ILs and hemicellulose during dissolution was examined by employing the ${ }^{13} \mathrm{C}$ NMR technique to obtain the changes in the chemical shifts of carbons in the hemicellulose and ILs at $25{ }^{\circ} \mathrm{C}$. The ${ }^{13} \mathrm{C}$ NMR spectrum of the original hemicellulose is shown in Fig. 5a. The peaks at $102.22 \mathrm{ppm}, 75.82 \mathrm{ppm}, 74.48$ ppm, $73.08 \mathrm{ppm}$, and $63.75 \mathrm{ppm}$ were attributed to XC1, XC4, XC3, XC2, and XC5 of the xylopyranose unit of the hemicellulose, respectively (Peng et al. 2012). Because of the low concentration of hemicellulose in the DMSO- $\mathrm{d}_{6}$ solution $(20 \mathrm{mg}$ of hemicellulose dissolved in $0.5 \mathrm{~mL}$ of DMSO- $\mathrm{d}_{6}$ ) and the low relative content of arabinose in hemicellulose (Table $3)$, the ${ }^{13} \mathrm{C}$ NMR signals for arabinose were weak and could not be detected. Therefore, only the chemical shift change for the xylopyranose unit of the hemicellulose was considered. The ${ }^{13} \mathrm{C}$ NMR spectra of the pure $\mathrm{BmimCl}$ and mixture of $\mathrm{BmimCl}+$ hemicellulose are presented in Figs. 5b and 5c. The NMR signals for the pure BmimCl, $\mathrm{BmimBr}$, and BmimI were assigned according to the literature (Xu et al. 2010, 2014). Moreover, the changes in the NMR data are summarized in Tables 5 and 6.

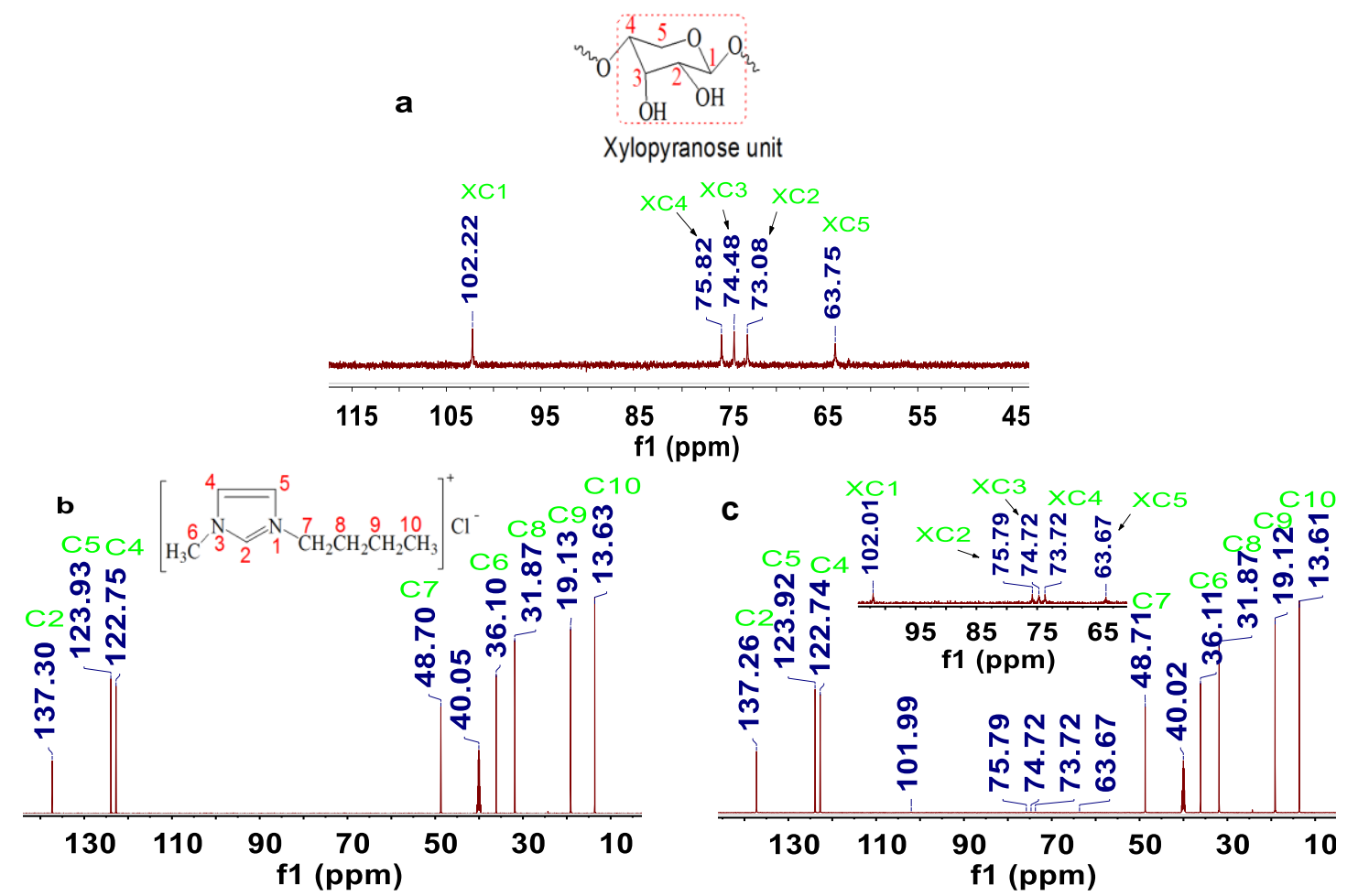

Fig. 5. ${ }^{13} \mathrm{C}$ NMR spectra of the original hemicellulose (a), pure $\mathrm{BmimCl}(\mathrm{b})$, and mixture of $\mathrm{BmimCl}+$ hemicellulose $(\mathrm{c})\left(25^{\circ} \mathrm{C}, \mathrm{DMSO}-\mathrm{d}_{6}\right)$

The ${ }^{13} \mathrm{C}$ NMR chemical shifts of the solvent DMSO- $\mathrm{d}_{6}$ and the imidazolium cations of the ILs in the pure liquid and mixture of IL + hemicellulose are shown in Table 5. The change in the chemical shift for all of the carbons of solvent DMSO- $\mathrm{d}_{6}$ and the imidazolium cations could have been neglected $(-0.05 \mathrm{ppm}<\Delta \delta<0.05 \mathrm{ppm})$. These findings demonstrated that there was no synergistic interactions occured with the deuterated solvent. DMSO- $\mathrm{d}_{6}$ only had the function of solvent and mainly served to dissociate the ion pairs in ILs into solvated cations and anions (Xu and Zhang 2015). This result also suggested that almost no interaction, such as the formation of hydrogen bonds, occurred between the 
imidazolium cation and hemicellulose. Hence, the imidazolium cation 1-butyl-3-methylimidazolium did not play an important role in the dissolution of hemicellulose in the ILs. Otherwise, the interaction between the hemicellulose and ILs would have caused redistribution of the electron cloud density around the $\mathrm{C} 2$ to $\mathrm{C} 10$ atoms and subsequently the corresponding change of chemical shifts.

Table 5. ${ }^{13} \mathrm{C}$ NMR Chemical Shifts of the Solvent DMSO-d 6 and the Imidazolium Cations of the ILs in the Pure Liquid and Mixture of IL + Hemicellulose

\begin{tabular}{|c|c|c|c|c|c|c|c|c|c|}
\hline & \multicolumn{9}{|c|}{ Chemical Shift $(\delta, \mathrm{ppm})$} \\
\hline & \multirow{2}{*}{$\mathrm{DMSO}^{-\mathrm{d}_{6}}$} & \multicolumn{8}{|c|}{ Imidazolium Cations of the ILs } \\
\hline & & $\mathrm{C} 2$ & C4 & C5 & $\mathrm{C} 6$ & $\mathrm{C} 7$ & $\mathrm{C} 8$ & C9 & $\mathrm{C} 10$ \\
\hline $\begin{array}{c}\text { BmimCl + } \\
\text { Hemicellulose }\end{array}$ & 40.02 & 137.26 & 122.74 & 123.92 & 36.11 & 48.71 & 31.87 & 19.12 & 13.61 \\
\hline $\mathrm{BmimCl}$ & 40.05 & 137.30 & 122.75 & 123.93 & 36.10 & 48.70 & 31.87 & 19.13 & 13.63 \\
\hline$\Delta \delta$ & -0.03 & -0.04 & -0.01 & -0.01 & +0.01 & +0.01 & 0.00 & -0.01 & -0.02 \\
\hline $\begin{array}{c}\mathrm{BmimBr}+ \\
\text { Hemicellulose }\end{array}$ & 40.04 & 136.92 & 122.65 & 123.84 & 36.34 & 48.84 & 31.84 & 19.11 & 13.65 \\
\hline $\mathrm{BmimBr}$ & 40.06 & 136.94 & 122.67 & 123.86 & 36.31 & 48.84 & 31.84 & 19.13 & 13.66 \\
\hline$\Delta \delta$ & -0.02 & -0.02 & -0.02 & -0.02 & +0.02 & 0.00 & 0.00 & -0.02 & -0.01 \\
\hline $\begin{array}{c}\text { Bmiml + } \\
\text { Hemicellulose }\end{array}$ & 40.12 & 136.82 & 122.62 & 123.85 & 36.64 & 49.01 & 31.77 & 19.16 & 13.73 \\
\hline Bmiml & 40.15 & 136.82 & 122.63 & 123.87 & 36.62 & 49.01 & 31.77 & 19.16 & 13.73 \\
\hline$\Delta \delta$ & -0.03 & 0.00 & -0.01 & -0.02 & +0.02 & 0.00 & 0.00 & 0.00 & 0.00 \\
\hline
\end{tabular}

Table 6 shows that the chemical shifts of carbons on the xylopyranose unit of the hemicellulose changed remarkably. The signal of the XC2 atom moved distinctly downfield (an increase in the chemical shift). The $\mathrm{Cl}^{-}, \mathrm{Br}^{-}$, and $\mathrm{I}^{-}$of the ILs most probably interacted with the hydroxyl proton at the XC2 position to form hydrogen bonds, which resulted in a reduced electron cloud density around the corresponding XC2 and an increase in the chemical shift value (Xu et al. 2010; Chen et al. 2011). Moreover, Table 5 indicates that the change in the chemical shift for XC2 on the xylopyranose unit of the hemicellulose in the mixture of $\mathrm{IL}+$ hemicellulose was in the following order: $\mathrm{BmimCl}>\mathrm{BmimBr}>$ BmimI. With an increase in the $\beta$ value of the anion (Table 1), the change in the chemical shift for XC2 increased. Also, the increase in the chemical shift for the XC2 atom was more evident than that for the XC3 atom on the xylopyranose unit. This phenomenon indicated that the anions preferentially interacted with the hydroxy protons at the XC2 atom to form hydrogen bonds. Another possible reason was the presence of arabinose attached at the $\mathrm{O}$ 3 position of the xylopyransyl units (Ebringerová et al. 1992). Thus, the number of hydroxy protons at XC3 to form hydrogen bonds with anions was smaller than that at XC2. Furthermore, compared with the downfield of the signal of the XC3 atom of the hemicellulose in the mixture of $\mathrm{BmimCl}+$ hemicellulose, the signals of the $\mathrm{XC} 3$ atom of the hemicellulose in the mixtures of $\mathrm{BmimBr}+$ hemicellulose and $\mathrm{BmimI}+$ hemicellulose moved upfield. This event led to corresponding reductions of $0.05 \mathrm{ppm}$ and $0.13 \mathrm{ppm}$ in the chemical shifts. One possible reason was the inability of $\mathrm{Br}^{-}$and $\mathrm{I}^{-}$to interact with the hydroxyl proton at the XC3 position because of their weak hydrogen bond-accepting ability. At the same time, the interaction between the hydroxyl proton at $\mathrm{XC} 2$ and $\mathrm{Br}^{-} / \mathrm{I}^{-}$ probably caused an increase in the electron cloud density around the XC3 atom. Hence, the variation in the chemical shifts for the $\mathrm{XC} 2$ and $\mathrm{XC} 3$ atoms of the hemicellulose in the 
mixtures of ILs + hemicellulose was consistent with those of the hemicellulose solubilities in the three ILs (Table 1). Considering the Kamlet-Taft $\beta$ parameters obtained by Lungwitz and Spange (2008), when the hydrogen bond-accepting ability of the anions of ILs was stronger, the ability was stronger to form hydrogen bonds with the hydroxyl protons of the $\mathrm{XC} 2$ and $\mathrm{XC} 3$ atoms of the hemicellulose. This characteristic resulted in a higher solubility. Simultaneously, the electron cloud density was redistributed because of the destruction of the inter- and intra-chain hydrogen bonds in the hemicellulose. This phenomenon resulted in a change in the chemical shifts of the other carbon atoms, such as XC1, XC4, and XC5. Hence, the interaction between the anion in the ILs and hemicellulose by forming hydrogen bonds remarkably affected the solubility of the hemicellulose in the ILs (Youngs et al. 2011).

Table 6. ${ }^{13} \mathrm{C}$ NMR Chemical Shifts of the Xylopyranose Unit of Hemicellulose in the Original State and Mixture of IL + Hemicellulose

\begin{tabular}{|c|c|c|c|c|c|}
\hline \multirow{2}{*}{} & \multicolumn{5}{|c|}{ Chemical Shift $(\delta, \mathrm{ppm})$} \\
\cline { 2 - 6 } & XC1 & XC2 & XC3 & XC4 & XC5 \\
\hline Hemicellulose & 102.22 & 73.08 & 74.48 & 75.82 & 63.75 \\
\hline BmimCl + Hemicellulose & 101.99 & 73.72 & 74.72 & 75.79 & 63.70 \\
\hline$\Delta \delta$ & -0.23 & +0.64 & +0.34 & -0.03 & -0.05 \\
\hline \multicolumn{5}{|l|}{} \\
\hline BmimBr + Hemicellulose & 101.97 & 73.37 & 74.43 & 75.95 & 63.68 \\
\hline$\Delta \delta$ & -0.25 & +0.29 & -0.05 & +0.13 & -0.07 \\
\hline \multicolumn{5}{|l|}{} \\
\hline Bmiml + Hemicellulose & 101.96 & 73.27 & 74.35 & 75.91 & 63.74 \\
\hline$\Delta \delta$ & -0.26 & +0.19 & -0.13 & +0.09 & -0.01 \\
\hline
\end{tabular}

\section{CONCLUSIONS}

1. In this study, the solubilities of the bamboo hemicellulose in $\mathrm{BmimCl}, \mathrm{BmimBr}$, and BmimI were measured as a function of the temperature. Representative hemicellulose with solubilities higher than $9.00 \mathrm{~g} / 100 \mathrm{~g}$ of ionic liquid (IL) were regenerated from $\mathrm{BmimCl}$ and $\mathrm{BmimBr}$ at a saturated point and then characterized. The ${ }^{1} \mathrm{H} \mathrm{NMR}$ and ${ }^{13} \mathrm{C}$ NMR techniques were performed to elucidate the interaction between the hemicellulose and ILs.

2. The anion structure and temperature markedly affected the solubility. The solubility of hemicellulose in the three ILs had the follwing order: $\mathrm{BmimCl}>\mathrm{BmimBr}>\mathrm{BmimI}$. When the temperature increased from $80{ }^{\circ} \mathrm{C}$ to $150{ }^{\circ} \mathrm{C}$, the solubility first increased and then decreased.

3. The gel permeation chromatography (GPC) results showed that the hemicellulose degraded slightly in the ILs. The neutral sugar analysis, FT-IR spectra, and TG results showed that the main chain of the hemicellulose was almost unchanged during dissolution. The regenerated hemicellulose exhibited structural features similar to those of the original hemicellulose. However, the thermal stability of hemicellulose slightly decreased after dissolution treatment by the ILs. 
4. According to the ${ }^{13} \mathrm{C}$ NMR analysis, a hydrogen bond possibly formed between the anion of the ILs and hydroxyl proton of the hemicellulose, and this process resulted in the dissolution of hemicellulose in the ILs. The hydroxyl proton at XC2 of the xylopyranose units more easily formed a hydrogen bond with the ILs than the hydroxyl proton at XC3. The anion with a higher hydrogen bond-accepting ability more easily formed a hydrogen bond with the hemicellulose, and this phenomenon resulted in a higher solubility of the hemicellulose.

\section{ACKNOWLEDGMENTS}

This work was supported by the Natural Science Foundation of China (21666022) and the Natural Science Foundation from the Ministry of Education of Jiangxi Province of China (GJJ150189).

\section{REFERENCES CITED}

Arni, S. A. (2018). "Extraction and isolation methods for lignin separation from sugarcane bagasse: A review," Ind. Crop. Prod. 115, 330-339.

DOI: 10.1016/j.indcrop.2018.02.012

Brandt-Talbot, A., Gschwend, F. J. V., Fennell, P. S., Lammens, T. M., Tan, B., Weale, J., and Hallett, J. P. (2017). "An economically viable ionic liquid for the fractionation of lignocellulosic biomass," Green Chem. 19(13), 3078-3102.

DOI: 10.1039/C7GC00705A

Bylin, S., Olsson, C., Westman, G., and Theliander, H. (2014). "Solvation behavior of cellulose and xylan in the MIM/EMIMAc ionic liquid solvent system: Parameters for small-scale solvation," BioResources 9(1), 1038-1054.

DOI: 10.15376/biores.9.1.1038-1054

Cao, Y., Zhang, R., Cheng, T., Guo, J., Xian, M., and Liu, H. (2017). “Imidazoliumbased ionic liquids for cellulose pretreatment: Recent progresses and future perspectives," Appl. Microbiol. Biot. 101(2), 521-532.

DOI: $10.1007 / \mathrm{s} 00253-016-8057-8$

Castro, M. C., Arce, A., Soto, A., and Rodríguez, H. (2015). "Influence of methanol on the dissolution of lignocellulose biopolymers with the ionic liquid 1-ethyl-3methylimidazolium acetate," Ind. Eng. Chem. Res. 54(39), 9605-9614. DOI: 10.1021/acs.iecr.5b02604

Castro, R. C. d. A., Fonseca, B. G., dos Santos, H. T. L., Ferreira, I. S., Mussatto, S. I., and Roberto, I. C. (2017). "Alkaline deacetylation as a strategy to improve sugars recovery and ethanol production from rice straw hemicellulose and cellulose," Ind. Crop. Prod. 106, 65-73. DOI: 10.1016/j.indcrop.2016.08.053

Chen, Q., Xu, A., Li, Z., Wang, J., and Zhang, S. (2011). "Influence of anionic structure on the dissolution of chitosan in 1-butyl-3-methylimidazolium-based ionic liquids," Green Chem. 13(12), 3446-3452. DOI: 10.1039/C1GC15703E

Deshpande, R., Giummarella, N., Henriksson, G., Germgård, U., Sundvall, L., Grundberg, H., and Lawoko, M. (2018). "The reactivity of lignin carbohydrate complex (LCC) during manufacture of dissolving sulfite pulp from softwood," Ind. Crop. Prod. 115, 315-322. DOI: 10.1016/j.indcrop.2018.02.038 
Du, J., Li, C., Zhao, Y., and Wang, H. (2018). "Hemicellulose isolated from waste liquor of viscose fiber mill for preparation of polyacrylamide-hemicellulose hybrid films," Int. J. Biol. Macromol. 108, 1255-1260. DOI: 10.1016/j.ijbiomac.2017.11.036

Ebringerová, A., Hromádková, Z., Alföldi, J., and Berth, G. (1992). "Structural and solution properties of corn cob heteroxylans," Carbohydr. Polym. 19(2), 99-105. DOI: 10.1016/0144-8617(92)90119-B

Eisenhuber, K., Krennhuber, K., Steinmüller, V., and Jäger, A. (2013). "Comparison of different pre-treatment methods for separating hemicellulose from straw during lignocellulose bioethanol production," Enrgy. Proced. 40, 172-181.

DOI: 10.1016/j.egypro.2013.08.021

Froschauer, C., Hummel, M., Laus, G., Schottenberger, H., Sixta, H., Weber, H. K., and Zuckerstätter, G. (2012). "Dialkyl phosphate-related ionic liquids as selective solvents for xylan," Biomacromolecules 13(6), 1973-1980. DOI: 10.1021/bm300582s

Gupta, S., Madan, R. N., and Bansal, M. C. (1987). "Chemical composition of Pinus caribaea hemicellulose," Tappi J. 70(8), 113-116.

Hart, W. E. S., Harper, J. B., and Aldous, L. (2015). "The effect of changing the components of an ionic liquid upon the solubility of lignin," Green Chem. 17(1), 214-218. DOI: 10.1039/C4GC01888E

Hutterer, C., Schild, G., and Potthast, A. (2016). "A precise study on effects that trigger alkaline hemicellulose extraction efficiency," Bioresour. Technol. 214, 460-467. DOI: 10.1016/j.biortech.2016.04.114

Ji, W., Ding, Z., Liu, J., Song, Q., Xia, X., Gao, H., Wang, H., and Gu, W. (2012). "Mechanism of lignin dissolution and regeneration in ionic liquid," Energ. Fuel. 26(10), 6393-6403. DOI: 10.1021/ef301231a

Kačuráková, M., Ebringerová, A., Hirsch, J., and Hromádková, Z. (1994). “Infrared study of arabinoxylans," J. Sci. Food Agr. 66(3), 423-427. DOI: 10.1002/jsfa.2740660323

Liu, Y., Sun, B., Zheng, X., Yu, L., and Li, J. (2018). "Integrated microwave and alkaline treatment for the separation between hemicelluloses and cellulose from cellulosic fibers," Bioresour. Technol. 247, 859-863. DOI: 10.1016/j.biortech.2017.08.059

Lodish, H., Berk, A., Zipursky, L. S., Matsudaira, P., Baltimore, D., and Darnell, J. (2000). "The dynamic plant cell wall," in: Molecular Cell Biology, $4^{\text {th }}$ Edition, W. J. Freeman, New York, NY, pp. 231-234

López-Linares, J. C., Romero, I., Cara, C., Castro, E., and Mussatto, S. I. (2018). "Xylitol production by Debaryomyces hansenii and Candida guilliermondii from rapeseed straw hemicellulosic hydrolysate," Bioresour. Technol. 247, 736-743.

DOI: 10.1016/j.biortech.2017.09.139

Lu, B., Xu, A., and Wang, J. (2014). "Cation does matter: How cationic structure affects the dissolution of cellulose in ionic liquids," Green Chem. 16(3), 1326-1335. DOI: $10.1039 / \mathrm{C} 3 \mathrm{GC} 41733 \mathrm{~F}$

Lungwitz, R., and Spange, S. (2008). "A hydrogen bond accepting (HBA) scale for anions, including room temperature ionic liquids," New J. Chem. 32(3), 392-394. DOI: $10.1039 / \mathrm{b} 714629 \mathrm{a}$

Magnin, J.-P., Papaiconomou, N., and Billard, I. (2018). "Polyphenol, polysaccharide and lactate extraction from pulping factory black liquor by ionic liquids," Sep. Purif. Technol. 196, 140-148. DOI: 10.1016/j.seppur.2017.08.012

Mazar, A., Jemaa, N., Al Dajani, W. W., Marinova, M., and Perrier, M. (2018). "Comparative study: Furfural production from two types of pre-hydrolysates produced using aspen and maple chips," Biomass Bioenerg. 111, 103-113. 
DOI: 10.1016/j.biombioe.2018.02.013

Mohtar, S. S., Busu, T. N. Z. T. M., Noor, A. M. M., Shaari, N., and Mat, H. (2017). “An ionic liquid treatment and fractionation of cellulose, hemicellulose and lignin from oil palm empty fruit bunch," Carbohydr. Polym. 166, 291-299.

DOI: 10.1016/j.carbpol.2017.02.102

Moyer, P., Smith, M. D., Abdoulmoumine, N., Chmely, S. C., Smith, J. C., Petridis, L., and Labbé, N. (2018). "Relationship between lignocellulosic biomass dissolution and physicochemical properties of ionic liquids composed of 3-methylimidazolium cations and carboxylate anions," Phys. Chem. Chem. Phys. 20(4), 2508-2516. DOI: $10.1039 / \mathrm{c} 7 \mathrm{cp} 07195 \mathrm{~g}$

Payal, R. S., Bharath, R., Periyasamy, G., and Balasubramanian, S. (2012). "Density functional theory investigations on the structure and dissolution mechanisms for cellobiose and xylan in an ionic liquid: Gas phase and cluster calculations," J. Phys. Chem. B 116(2), 833-840. DOI: 10.1021/jp207989w

Peng, H., Wang, N., Hu, Z., Yu, Z., Liu, Y., Zhang, J., and Ruan, R. (2012). "Physicochemical characterization of hemicelluloses from bamboo (Phyllostachys pubescens Mazel) stem," Ind. Crop. Prod. 37(1), 41-50.

DOI: 10.1016/j.indcrop.2011.11.031

Peng, X., Ren, J., Zhong, L., and Sun, R. (2011). "Homogeneous synthesis of hemicellulosic succinates with high degree of substitution in ionic liquid," Carbohydr. Polym. 86(4), 1768-1774. DOI: 10.1016/j.carbpol.2011.07.018

Santos, T. M., Alonso, M. V., Oliet, M., Dominguez, J. C., Rigual, V., and Rodriguez, F. (2018). "Effect of autohydrolysis on Pinus radiata wood for hemicellulose extraction," Carbohydr. Polym. 194, 285-293. DOI: 10.1016/j.carbpol.2018.04.010

Stoffel, R. B., Neves, P. V., Felissia, F. E., Ramos, L. P., Gassa, L. M., and Area, M. C. (2017). "Hemicellulose extraction from slash pine sawdust by steam explosion with sulfuric acid," Biomass Bioenerg. 107, 93-101. DOI: 10.1016/j.biombioe.2017.09.019

Vitz, J., Erdmenger, T., Haensch, C., and Schubert, U. S. (2009). "Extended dissolution studies of cellulose in imidazolium based ionic liquids," Green Chem. 11(3), 417424. DOI: $10.1039 / \mathrm{B} 818061 \mathrm{~J}$

Xu, A., Wang, J., and Wang, H. (2010). "Effects of anionic structure and lithium salts addition on the dissolution of cellulose in 1-butyl-3-methylimidazolium-based ionic liquid solvent system," Green Chem. 12(2), 268-275. DOI: 10.1039/B916882F

$\mathrm{Xu}, \mathrm{A}$., and Zhang, Y. (2015). "Insight into dissolution mechanism of cellulose in $\left[\mathrm{C}_{4} \mathrm{mim}\right]\left[\mathrm{CH}_{3} \mathrm{COO}\right] / \mathrm{DMSO}$ solvent by ${ }^{13} \mathrm{C}$ NMR spectra," J. Mol. Liq. 1088, 101104. DOI: $10.1016 /$ j.molstruc.2015.02.031

Xu, A., Zhang, Y., Liu, W., Yao, K., and Xu, H. (2014). "Effect of alkyl chain length in anion on dissolution of cellulose in 1-butyl-3-methylimidazolium carboxylate ionic liquids," J. Mol. Liq. 197, 211-214. DOI: 10.1016/j.molliq.2014.05.018

Yang, D., Zhong, L.-X., Yuan, T.-Q., Peng, X.-W., and Sun, R.-C. (2013). "Studies on the structural characterization of lignin, hemicelluloses and cellulose fractionated by ionic liquid followed by alkaline extraction from bamboo," Ind. Crop. Prod. 43, 141149. DOI : 10.1016/j.indcrop.2012.07.024

Youngs, T. G. A., Holbrey, J. D., Mullan, C. L., Norman, S. E., Lagunas, M. C., D’Agostino, C., Mantle, M. D., Gladden, L. F., Bowron, D. T., and Hardacre, C. (2011). "Neutron diffraction, NMR and molecular dynamics study of glucose dissolved in the ionic liquid 1-ethyl-3-methylimidazolium acetate," Chem. Sci. 2(8), 1594-1605. DOI: 10.1039/C1SC00241D 
Zavrel, M., Bross, D., Funke, M., Büchs, J., and Spiess, A. C. (2009). "High-throughput screening for ionic liquids dissolving (lingo-)cellulose," Bioresour. Technol. 100(9), 2580-2587. DOI: 10.1016/j.biortech.2008.11.052

Zhao, H., Baker, G. A., and Cowins, J. V. (2010). "Fast enzymatic saccharification of switchgrass after pretreatment with ionic liquids," Biotechnol. Progr. 26(1), 127-133. DOI: $10.1002 / \mathrm{btpr} .331$

Zhao, Y., Liu, X., Wang, J., and Zhang, S. (2013). "Effects of anionic structure on the dissolution of cellulose in ionic liquids revealed by molecular simulation," Carbohydr. Polym. 94(2), 723-730. DOI: 10.1016/j.carbpol.2013.02.011

Article submitted: November 17, 2018; Peer review completed: January 19, 2019; Revised version received and accepted: January 23, 2019; Published: January 28, 2019.

DOI: 10.15376/biores.14.1.2097-2112 